\title{
Asymptomatic Severe Aortic Stenosis with Left Ventricular Dysfunction: Watchful Waiting or Valve Replacement?
}

\author{
Larry E. Miller, PhD; Valerie M. Miller; and Larry D. Acers, BS
}

\begin{abstract}
Aortic stenosis (AS) is the most common valvular heart disorder in older adults. Patients with severe AS are generally treated nonsurgically if asymptomatic and referred to aortic valve replacement when symptoms develop. However, patients with severe asymptomatic AS with left ventricular dysfunction may benefit from early aortic valve replacement. Although operative mortality in patients with severe AS and left ventricular dysfunction is greater than in patients with preserved left ventricular function, the overall mortality risk is substantially lower than that of watchful waiting. Operative risk in patients with severe AS and left ventricular dysfunction is often overestimated and, consequently, most are not referred to surgery despite clinical data in support of early aortic valve replacement. Asymptomatic patients with echocardiographic confirmation of severe AS and left ventricular dysfunction should be referred for aortic valve replacement.
\end{abstract}

Keywords: Aortic stenosis; Aortic valve replacement; Heart failure; Heart valve

Corresponding Author:

Larry E. Miller, PhD

Miller Scientific Consulting, Inc.

26 Portobello Road

Arden, NC 28704 USA

Tel: (928) 607-9657

Fax: (928) 268-3563

Email: larry@millerscientific.com

Received: November 19, 2012

Revised: January 18, 2013

Accepted: January 23, 2013

Published online ahead of print: April II, 2013

doi: $10.3121 / \mathrm{cmr} .2013 .1134$
A adults, and it can be categorized as mild, moderate, or severe using established echocardiographic criteria. According to the American College of Cardiology and the American Heart Association (ACC/AHA) Task Force, severe AS is defined as aortic valve area $<1.0 \mathrm{~cm}^{2}$, mean gradient $>40 \mathrm{~mm} \mathrm{Hg}$, or jet velocity $>4.0 \mathrm{~m} / \mathrm{s}$. However, the primary determinant of the need for aortic valve replacement (AVR) is not based on these criteria, but instead on the presence or absence of AS-related symptoms including angina, dyspnea, or syncope. With few exceptions, symptomatic patients should be referred for AVR. Asymptomatic patients are frequently advised to continue "watchful waiting," with annual echocardiograms recommended for those with severe AS. These decisions are largely based on the low risk of sudden death $(\sim 1 \%$ per year) in asymptomatic patients and the grave prognosis when symptoms develop, with the risk of sudden death increasing exponentially, and mean survival of only 2 to 3 years without AVR. ${ }^{1}$ However, asymptomatic patients present with marked heterogeneity, such that certain subsets benefit from early AVR.

In severe, asymptomatic AS patients, freedom from symptoms and cardiac events ranges from $59 \%$ to $86 \%$ at 1 year, $56 \%$ to $67 \%$ at 2 years, and $33 \%$ to $59 \%$ at 5 years. $^{2-5}$ Consequently, the average period between severe AS diagnosis and symptom or event onset can be estimated at 3 to 4 years. In asymptomatic patients with AS and normal left ventricle (LV) function, the risks of AVR greatly outweigh any potential benefit, specifically because operative mortality with isolated AVR generally ranges from $2 \%$ to $4 \%$, whereas the risk of sudden death in an asymptomatic patient is less than $1 \%$ per year based on large prospective 
series. ${ }^{2}$ However, asymptomatic patients with LV dysfunction, accounting for $0.4 \%$ of patients with severe AS, ${ }^{6}$ may benefit from AVR before the onset of AS symptoms despite opinions to the contrary.

Importantly, patients who claim to be asymptomatic may, in fact, experience symptoms that they do not report or that are not appreciated due to activity restrictions. Exercise stress testing is a safe, underutilized tool that may help to clarify symptomatology and demonstrates excellent prognostic utility. More than $30 \%$ of patients who claim to be asymptomatic do, in fact, experience symptoms during graded exercise testing. Furthermore, if symptoms are elicited during graded exercise testing, prognosis is poor with 2-year event-free survival of only $19 \%$ versus $85 \%$ in patients with no symptoms. On balance, the prognostic value of symptoms identified during exercise testing may be limited in the elderly (age $>70$ years).

The presence of symptoms at the time of surgery has no influence on operative or long-term mortality following AVR. Disregarding symptomatology as a potential target of treatment decision-making, the remaining influencers in this patient population include the risk of LV function decline during the watchful waiting period and the risk of sudden death during this period weighed against operative risks. It has been postulated that watchful waiting until symptom onset may result in irreversible myocardial fibrosis, ultimately compromising surgical outcomes with AVR, although the evidence in support of this notion is weak. Additionally, because the watchful waiting period is generally only a few years in duration, the chances of LV function declining to a degree whereby surgical risk is significantly elevated is low, with an estimated relative decrease in ejection fraction of $15 \%$ over 3 years in these patients. ${ }^{7}$ Assuming a patient with a preoperative ejection fraction of $35 \%$, the estimated reduction in ejection fraction to $30 \%$ would increase the relative risk (not absolute risk) of surgical mortality by less than $5 \%$. This leaves the balance between watchful waiting mortality and operative mortality as the main influencer of treatment outcome for asymptomatic AS patients with LV dysfunction.

It is well established that operative mortality in patients with severe AS and LV dysfunction is greater than in those with preserved LV function. In patients with LV dysfunction, relative mortality risk increases $1 \%$ for every $1 \%$ decrease in ejection fraction. ${ }^{8}$ This elevated risk was realized in several recent series of patients with severe AS and LV dysfunction undergoing AVR with reported mortality rates ranging from $8 \%$ to $21 \% .^{9}$ Longer term data in these patients are similarly inferior to their normal LV function counterparts, with $48 \%$ mortality reported over a mean 2.4 years following AVR. However, this mortality rate remains much lower than the $73 \%$ mortality risk reported for watchful waiting over the same period. ${ }^{10}$ A study that included 159 nonoperated patients with severe AS and ejection fraction $\leq 40 \%$ reported similarly dismal mortality rates, including almost $60 \%$ at 1 year, $70 \%$ at 3 years, and $80 \%$ at 5 years. ${ }^{7}$ In a study of nearly 1000 patients with severe AS, among those who were asymptomatic, 1 -year survival in operated patients was $94 \%$, versus $78 \%$ for those who did not undergo AVR. ${ }^{11}$ Interestingly, LV dysfunction had no influence on patient survival.

Patients with severe AS and LV dysfunction may be risk stratified with dobutamine stress echocardiography using estimates of contractile reserve and aortic valve gradient. Hemodynamic response to dobutamine challenge can be classified as follows: (a) valve gradient increase $>40 \mathrm{~mm} \mathrm{Hg}$, indicating severe AS; (b) normalized cardiac output with low valve gradient $(<30 \mathrm{~mm} \mathrm{Hg}$ ), indicative of cardiomyopathy and milder AS; or (c) no appreciable change in stroke volume, cardiac output, or valve gradient, which indicates poor contractile reserve. Although patients with poor contractile reserve have the worst prognosis, surgical mortality remains substantially lower than with no treatment. ${ }^{12,13}$

Many surgeons overestimate surgical risk in patients with asymptomatic severe AS with LV dysfunction. Consequently, most of these patients are not referred to surgery, citing prohibitive operative risk despite superior outcomes in those undergoing AVR. ${ }^{14-16}$ Despite a higher risk than in patients with preserved ejection fraction, overall, the risk of doing nothing clearly outweighs the risk of AVR in this patient cohort. The recent advent of transcatheter aortic valve replacement (TAVR) offers a promising treatment alternative for patients with severe AS. However, TAVR is only indicated in symptomatic patients who are determined to be inoperable for AVR and, therefore, is irrelevant to the topic of asymptomatic patients. In the absence of previous (and likely future) randomized controlled trials to guide decision making, asymptomatic patients with echocardiographically confirmed severe AS and LV dysfunction, regardless of transvalvular gradient or contractile reserve, should be referred for AVR.

\section{References}

1. Iivanainen AM, Lindroos M, Tilvis R, Heikkila J, Kupari M. Natural history of aortic valve stenosis of varying severity in the elderly. Am J Cardiol 1996;78:97-101.

2. Rosenhek R, Binder T, Porenta G, Lang I, Christ G, Schemper M, Maurer G, Baumgartner H. Predictors of outcome in severe, asymptomatic aortic stenosis. N Engl J Med 2000;343:611-617.

3. Kelly TA, Rothbart RM, Cooper CM, Kaiser DL, Smucker ML, Gibson RS. Comparison of outcome of asymptomatic to symptomatic patients older than 20 years of age with valvular aortic stenosis. Am J Cardiol 1988;61:123-130.

4. Pellikka PA, Sarano ME, Nishimura RA, Malouf JF, Bailey KR, Scott CG, Barnes ME, Tajik AJ. Outcome of 622 adults with asymptomatic, hemodynamically significant aortic stenosis during prolonged follow-up. Circulation 2005; 111:3290-3295.

5. Pellikka PA, Nishimura RA, Bailey KR, Tajik AJ. The natural history of adults with asymptomatic, hemodynamically significant aortic stenosis. J Am Coll Cardiol 1990; 15:1012-1017. 
6. Henkel DM, Malouf JF, Connolly HM, Michelena HI, Sarano ME, Schaff HV, Scott CG, Pellikka PA. Asymptomatic left ventricular systolic dysfunction in patients with severe aortic stenosis: characteristics and outcomes. J Am Coll Cardiol 2012;60:2325-2329.

7. Varadarajan P, Kapoor N, Bansal RC, Pai RG. Clinical profile and natural history of 453 nonsurgically managed patients with severe aortic stenosis. Ann Thorac Surg 2006; 82:2111-2115.

8. Pai RG, Kapoor N, Bansal RC, Varadarajan P. Malignant natural history of asymptomatic severe aortic stenosis: benefit of aortic valve replacement. Ann Thorac Surg 2006; 82:2116-2122.

9. Borowski A, Ghodsizad A, Vchivkov I, Gams E. Surgery for severe aortic stenosis with low transvalvular gradient and poor left ventricular function -- a single centre experience and review of the literature. J Cardiothorac Surg 2007;2:9.

10. Pai RG, Varadarajan P, Razzouk A. Survival benefit of aortic valve replacement in patients with severe aortic stenosis with low ejection fraction and low gradient with normal ejection fraction. Ann Thorac Surg 2008;86:1781-1789.

11. Bach DS. Prevalence and characteristics of unoperated patients with severe aortic stenosis. J Heart Valve Dis 2011; 20:284-291.

12. Monin JL, Monchi M, Gest V, Duval-Moulin AM, DuboisRande JL, Gueret P. Aortic stenosis with severe left ventricular dysfunction and low transvalvular pressure gradients: risk stratification by low-dose dobutamine echocardiography. J Am Coll Cardiol 2001;37:2101-2107.

13. Monin JL, Quere JP, Monchi M, Petit H, Baleynaud S, Chauvel C, Pop C, Ohlmann P, Lelguen C, Dehant P, Tribouilloy C, Gueret P. Low-gradient aortic stenosis: operative risk stratification and predictors for long-term outcome: a multicenter study using dobutamine stress hemodynamics. Circulation 2003;108:319-324.

14. Bach DS, Cimino N, Deeb GM. Unoperated patients with severe aortic stenosis. J Am Coll Cardiol 2007;50:2018-2019.

15. Iung B, Cachier A, Baron G, Messika-Zeitoun D, Delahaye F, Tornos P, Gohlke-Barwolf C, Boersma E, Ravaud P, Vahanian A. Decision-making in elderly patients with severe aortic stenosis: why are so many denied surgery? Eur Heart J 2005;26:2714-2720.

16. Bouma BJ, van Den Brink RB, van Der Meulen JH, Verheul HA, Cheriex EC, Hamer HP, Dekker E, Lie KI, Tijssen JG. To operate or not on elderly patients with aortic stenosis: the decision and its consequences. Heart 1999;82:143-148.

\section{Author Affiliations}

Larry E. Miller, PhD*; Valerie M. Miller*;

and Larry D. Acers, $B S^{*}$

*Miller Scientific Consulting, Inc., Arden, NC, USA 